\title{
Correlation between density of metallic glasses and dynamic fragility of metallic glass-forming liquids
}

\author{
R. J. Xue ${ }^{1,2}$, L. Z. Zhao ${ }^{1}$, M. X. Pan ${ }^{1}$, B. Zhang ${ }^{2, *}$, W. H. Wang ${ }^{1, *}$ \\ ${ }^{1}$ Institute of Physics, Chinese Academy of Sciences, Beijing 100190, China \\ ${ }^{2}$ School of Materials Science and Engineering, Hefei University of Technology, \\ Hefei 230009, China
}

\begin{abstract}
We study the density evolution upon isothermal annealing far below the glass transition temperature of various metallic glasses (MGs) with different fragility. We show that the density variation, which reflects the structural heterogeneity of MGs, has correlations with the Poisson's ratio and the kinetic fragility of their supercooled liquid state. The found relationship between the structure heterogeneity of metallic glasses and dynamic heterogeneity of their supercooled liquids has implications for understanding the structural heterogeneity and heredity, mechanical behaviors and nature of metallic glass.
\end{abstract}

*Contact authors: bo.zhang@hfut.edu.cn; whw@iphy.ac.cn 


\section{Introduction}

Density is a key concept in analyzing the structure of metallic glasses (MGs) and relies on the number and type of atoms and atoms combination bonding [1-4]. As one of the most available physical parameters, the density variation can also characterize the glass-forming ability and flow units evolution of MGs in isothermal relaxations [1-4]. Recent experimental and simulation evidences demonstrate that MGs have intrinsically microstructural heterogeneity, and the MGs contain the nano-scale liquid-like regions (termed as flow units) embedded in solid glassy matrix. The liquid like flow units have higher energy and lower elastic modulus compared to that of the glassy matrix, and the atoms in the flow unit move cooperatively and dissipate the energy under applied stress or temperature [5-17]. The structural heterogeneity of a MG can be reflected by the flow unit evolution, which can be characterized by the density variation under annealing temperature far below glass transition temperature $T_{\mathrm{g}}$. The density increases with the annealing time towards an equilibrium value which could reflect the evolution, annihilation and concentration variation of flow units and the degree of the structural heterogeneity in MGs [4, 18-20].

When glass-forming liquid is quickly cooled down to low temperature, its shear viscosity increases rapidly and reaches the maximum at $T_{g}$ on experimental timescales. The steepness of viscosity $(\eta)$ approaching $T_{g}$ and the sensitivity of the glass-forming liquid to temperature $(T)$ are markedly different among diverse glass-forming liquids [21-22], and the difference can be used to classify the glass-forming liquids. The liquid approximates Arrhenius behavior is considered to be stronger, while the liquid aggrandizingly deviated from Arrhenius behavior is regarded as fragile [21-23]. The parameter of fragility $m$ is defined as $m=\left.\frac{\partial \log \eta(T)}{\partial\left(T_{g} / T\right)}\right|_{T=T_{g}}$. The value of $m$ reflects how fragile of the liquid is, and the smaller value of fragility indicates that the liquid is less sensitive to the temperature change and stronger [23-25]. The fragile liquid has higher dynamic inhomogeneity.

It is widely accepted that the structural features of a MG inherits from its 
supercooled liquid state. The survey of the elastic, plastic, mechanical and physical properties and glass transition of various MGs indicates that MGs can inherit their properties from their base components [26-27]. Previous results show the structure of glass correlates with the fragility [24, 28], and the density variations of various glasses may be related to their fragility [4, 28]. It is suggested that the dynamic heterogeneity in supercooled liquids might be caused by some "defects" similar to those in the solid state [29]. It is intriguing to know if there is a correlation between the inhomogeneous structure and the fragility of the glass-forming liquids. However, the definite relationship between the density of MGs and the fragility of their metallic glass-forming liquids, which can indicate the connection of the structural and dynamic heterogeneities, is not clear yet.

In this paper, we study the density change upon isothermal annealing below $T_{g}$ associated with the structural heterogeneity or evolution of flow units in eight typical MGs with markedly different fragility. An interrelationship between the structural heterogeneity characterize by density variations and dynamic heterogeneity represents by fragility of glass-forming liquid is obtained indicating the structural features of a metallic glass inherits from its liquid state. We also discuss the connections among the structural and dynamic heterogeneities, the density evolution, the distribution of flow units and plasticity in MGs.

\section{Experimental}

$\mathrm{Cu}_{47} \mathrm{Zr}_{11} \mathrm{Ti}_{34} \mathrm{Ni}_{8}, \quad \mathrm{Pd}_{40} \mathrm{Ni}_{10} \mathrm{Cu}_{30} \mathrm{P}_{20}, \quad \mathrm{Zr}_{52.5} \mathrm{Cu}_{17.9} \mathrm{Ni}_{14.6} \mathrm{Al}_{10} \mathrm{Ti}_{5} \quad$ (vit105), $\left(\mathrm{Cu}_{50} \mathrm{Zr}_{50}\right)_{92} \mathrm{Al}_{8}, \quad \mathrm{Zr}_{65} \mathrm{Al}_{7.5} \mathrm{Ni}_{10} \mathrm{Cu}_{17.5}, \quad \mathrm{La}_{55} \mathrm{Al}_{25} \mathrm{Co}_{20}, \quad \mathrm{Ce}_{68} \mathrm{Al}_{10} \mathrm{Cu}_{20} \mathrm{Co}_{2} \quad$ and $\mathrm{Zr}_{61.5} \mathrm{Al}_{10.7} \mathrm{Ni}_{14.15} \mathrm{Cu}_{13.65}$ MGs with excellent glass-forming ability and different fragility [30-37] were selected. The master ingots with nominal compositions listed above were prepared by arc melting in a Ti-gettered argon atmosphere except the $\mathrm{Pd}_{40} \mathrm{Ni}_{10} \mathrm{Cu}_{30} \mathrm{P}_{20}$ ingot which was prepared by induction melting in a high-vacuum quartz tube. The alloy ingots were remelted and sucked into water cooled $\mathrm{Cu}$ mold to obtain cylindrical rods (with a diameter of $3 \mathrm{~mm}$ ) and glassy plates (with a thickness of $2 \mathrm{~mm}$ ) with a cooling rate of about $1000 \mathrm{~K} / \mathrm{s}$. The cross-section slice cut from the 
as-quenched sample rods were used for checking amorphicity by using X-ray diffraction (XRD) and differential scanning calorimetry (DSC). The broad diffraction peak without distinct sharp crystalline peaks in the XRD pattern indicates the amorphous structure of the alloys. The distinct glass transition and sharp crystallization behavior in the DSC curve of the same sample further confirm the glassy structure of the alloy. Due to the excellent glass forming ability of these selected MG systems, the amorphicity as well as its homogeneity was guaranteed.

The densities of the MGs were measured at room temperature using Archimedean technique. The weights of MG samples for the density measurements is larger than 1.0 gram. The working fluid was deionized water. The accuracy of density is within $0.1 \%$.

The Poisson's ratio $v$ of the MGs were measured at room temperature using resonant ultrasound spectroscopy (RUS). Rectangular samples with dimensions about $2 \times 2 \times 4 \mathrm{~mm}$ were placed between the piezoelectric transducers. Two independent elastic constants $C_{11}$ and $C_{44}$ were obtained to calculate the Poisson's ratio.

These MGs have wide supercooled liquid regions indicating high thermal stability upon annealing. All these samples of the MGs were isothermally annealed at $0.88 T_{g}$ for various times in a furnace under a high vacuum $\left(5 \times 10^{-5} \mathrm{~Pa}\right)$ and cooled down to room temperature for XRD, DSC, $v$ and density measurements.

\section{Results}

Figure 1 shows the measured density variation of the eight MGs for various iso-annealing times at the temperature of $0.88 T_{g}$. The density variation evolution of these MGs is similar but the relative density changes of the MGs $\Delta \rho=\left[\rho-\rho_{0}\right] / \rho_{0}$ [where $\rho_{0}$ and $\rho$ are the density of the as-cast and annealed MGs for time $t$, respectively] are markedly different. In the initial $10 \mathrm{hrs,} \mathrm{the} \mathrm{relative} \mathrm{density} \mathrm{change}$ increases rapidly. When time $t \rightarrow \infty$, the density change increase becomes slowly, and gradually approaches a saturation value $\Delta \rho(\infty)$, where the density of a MG reaches an equilibrium value for annealing fairly long time [38]. After $128 \mathrm{hrs}$ annealing, the 
relative density change $\Delta \rho$ is close to the saturation value $\Delta \rho(\infty)$, i.e. $\Delta \rho(128 \mathrm{hrs}) \approx$ $\Delta \rho(\infty)$ [4]. The saturation values $\Delta \rho(128 \mathrm{~h})$ of $\mathrm{Cu}_{47} \mathrm{Zr}_{11} \mathrm{Ti}_{34} \mathrm{Ni}_{8}, \mathrm{Pd}_{40} \mathrm{Ni}_{10} \mathrm{Cu}_{30} \mathrm{P}_{20}$, vit105, $\left(\mathrm{Cu}_{50} \mathrm{Zr}_{50}\right)_{92} \mathrm{Al}_{8}, \quad \mathrm{Zr}_{65} \mathrm{Al}_{7.5} \mathrm{Ni}_{10} \mathrm{Cu}_{17.5}, \quad \mathrm{La}_{55} \mathrm{Al}_{25} \mathrm{Co}_{20}, \mathrm{Ce}_{68} \mathrm{Al}_{10} \mathrm{Cu}_{20} \mathrm{Co}_{2}$ and $\mathrm{Zr}_{61.5} \mathrm{Al}_{10.7} \mathrm{Ni}_{14.15} \mathrm{Cu}_{13.65} \mathrm{MGs}$ are $0.822 \%, 0.536 \%, 0.418 \%, 0.436 \%, 0.31 \%, 0.25 \%$, $0.147 \%$ and $0.113 \%$, respectively. We also indicated the value of fragility of these MGs, which are obtained from the literatures [30-37] in Fig.1. One can see that the relative density change $\Delta \rho$ of the studied MGs is related to fragility $(\mathrm{m})$ of these MGs. The $\mathrm{Cu}_{47} \mathrm{Zr}_{11} \mathrm{Ti}_{34} \mathrm{Ni}_{8}$ with the biggest fragility value has the largest relative density change $\Delta \rho$, while the $\mathrm{Zr}_{61.5} \mathrm{Al}_{10.7} \mathrm{Ni}_{14.15} \mathrm{Cu}_{13.65}$ with the smallest value of $\Delta \rho$ has the smallest fragility.

Figure 2(a) presents the relationship between fragilities and relative density changes of these MGs annealed at $0.88 T_{\mathrm{g}}$ for $128 \mathrm{hrs}$. The fragility $m$ reflects diffusion rate of the atoms from high temperature to glass transition temperature $T_{\mathrm{g}}$ of metallic glass-forming liquid, indicating sensitivity, stability and dynamic heterogeneity of MG-forming liquid [21-25, 28]. The higher value of fragility indicates that the structure of the glass-forming liquid more sensitive to temperature change and the liquid has larger dynamic heterogeneity [21-23]. The $m$ of $\mathrm{Cu}_{47} \mathrm{Zr}_{11} \mathrm{Ti}_{34} \mathrm{Ni}_{8}$ (68)[30], $\mathrm{Pd}_{40} \mathrm{Ni}_{10} \mathrm{Cu}_{30} \mathrm{P}_{20}$ (58)[31], vit105 (49)[32], $\left(\mathrm{Cu}_{50} \mathrm{Zr}_{50}\right)_{92} \mathrm{Al}_{8}$ (43)[33], $\mathrm{Zr}_{65} \mathrm{Al}_{7.5} \mathrm{Ni}_{10} \mathrm{Cu}_{17.5}$ (35)[34], $\mathrm{La}_{55} \mathrm{Al}_{25} \mathrm{Co}_{20}$ (27)[35], $\mathrm{Ce}_{68} \mathrm{Al}_{10} \mathrm{Cu}_{20} \mathrm{Co}_{2}$ (21)[36] and $\mathrm{Zr}_{61.5} \mathrm{Al}_{10.7} \mathrm{Ni}_{14.15} \mathrm{Cu}_{13.65}$ (17)[37] MGs ranges from fragile to strong. The saturation values $\Delta \rho(128 \mathrm{~h})$ range from large to small depending on the fragility and have a roughly correlation with the values of $m$ for the eight MGs, indicating the correlation between the microstructure of MG and dynamic heterogeneity of metallic glass-forming liquid.

The Poisson's ratio $v$ (alternatively $K / G, K$ is bulk modulus; $G$ is shear modulus) is helpful for understanding the mechanisms of plastic flow of MGs. A clear correlation between Poisson's ratio $v$ and plasticity has been established in MG systems [39-43], and a MG with higher Poisson's ratio or lower $K / G$ has higher plasticity [42-43]. Figure 2(b) shows a relationship between Poisson's ratio $v$ and relative density change of these MGs annealed at $0.88 T_{\mathrm{g}}$ for $128 \mathrm{hrs}$. The MG with 
larger Poisson's ratio shows a larger relative density change and better plasticity, and vice versa. It was previously found that the fragility and Poisson's ratio in MGs had a correlation of $m=11.0(K / G-0.27)[41,44]$. These results indicates that the connection among the microstructure, the dynamic heterogeneity of metallic glass-forming liquid, and mechanical behaviors of MGs.

The evolution of flow units associated with the structural heterogeneity of MGs can also be characterized by the relative density change upon isothermal annealing below their $T_{\mathrm{g}}$. An empirical function for the density variation with the effective concentration of flow units is obtained for the MGs [4]:

$$
\rho=\frac{\rho(\infty)}{1+c},
$$

where $c$ correlates with the concentration of flow units of MGs and reflects the trends of microstructural attenuation with the increasing annealing time. The correlation has implications for understanding the connections among fragility, structural heterogeneity and mechanical behaviors in MGs [4]. From Eq.(1), the concentration evolution of flow unit $\Delta \mathrm{c}(128 \mathrm{~h})=c_{0}-c(128 \mathrm{~h})$ [where $c_{0}$ and $c(128 \mathrm{~h})$ correspond to concentration of flow units in as-cast state and annealed $\mathrm{MG}$ at $0.88 T_{\mathrm{g}}$ for $128 \mathrm{hrs}]$ of the $\mathrm{Cu}_{47} \mathrm{Zr}_{11} \mathrm{Ti}_{34} \mathrm{Ni}_{8}, \mathrm{Pd}_{40} \mathrm{Ni}_{10} \mathrm{Cu}_{30} \mathrm{P}_{20}$, vit105, $\left(\mathrm{Cu}_{50} \mathrm{Zr}_{50}\right)_{92} \mathrm{Al}_{8}$, $\mathrm{Zr}_{65} \mathrm{Al}_{7.5} \mathrm{Ni}_{10} \mathrm{Cu}_{17.5}, \mathrm{La}_{55} \mathrm{Al}_{25} \mathrm{Co}_{20}, \mathrm{Ce}_{68} \mathrm{Al}_{10} \mathrm{Cu}_{20} \mathrm{Co}_{2}$ and $\mathrm{Zr}_{61.5} \mathrm{Al}_{10.7} \mathrm{Ni}_{14.15} \mathrm{Cu}_{13.65} \mathrm{MG}$ annealed for $128 \mathrm{hrs}$ at $0.88 T_{\mathrm{g}}$ are obtained, which are $0.872 \%, 0.491 \%, 0.432 \%$, $0.378 \%, 0.303 \%, 0.264 \%, 0.118 \%$ and $0.109 \%$, respectively. Table I lists the fitting parameters for the relative concentration of flow units of these MGs.

Figure 3 gives the interrelationship between the relative density changes $\Delta \rho$ and flow units concentration variations $\Delta c$ of the MGs. The $\Delta \rho$ and $\Delta c$ show clear changing tendency or correlation. The fragile MGs with larger structural inhomogeneity, has larger density and flow units concentration changes in the same annealing condition. The inset exhibits the relationship between normalized density change $\rho / \rho_{0}$ and normalized concentration of flow units variation $c / c_{0}\left(c_{0}\right.$ and $c$ correspond to concentration of flow units of as-cast and annealed MGs for time $t$, respectively) upon annealing for various times. The evolution of $c$ and the relative 
density change of MGs with markedly different fragility and microstructural characteristics can be well fitted and have a linear relationship. The evolution tendency of density and concentration of flow units of each MG are similar: the MG which has lager relative density change also has larger variation of the concentration of flow units. The MG with smaller relative density change has smaller $\Delta c$. The results confirm that the relative density evolution upon annealing below $T_{g}$ of MGs is due to their intrinsic heterogeneous microstructure [4-13], which is correlated with dynamic heterogeneity of their glass-forming liquid. The microstructure heterogeneity of MG inherits from its supercooled liquid.

\section{Discussions}

Our above results indicate that the relative density variation can reflect the fragility property, flow unit activation and structural heterogeneity of a MG. The bigger $\Delta \rho$ means the structure of $\mathrm{MG}$ is more heterogeneous and has higher density of flow units, and vice versa. On the other hand, the fragile MG shows larger density change and larger relative concentration variation of flow units upon annealing because more flow units were annihilated during annealing in the more inhomogeneous MG, which is agreement with the previous predictions [40]. The correlation between $\Delta \rho$ and $m$ connects the structural heterogeneity of MGs with the dynamic heterogeneity of their supercooled liquid state.

The found correlations provide structural explanation on the Poisson's ratio criterion for the plasticity of MGs [40-42]. Based on the above correlations, the Poisson's ratio criterion intrinsically reflects the effect of the concentration of flow units on the plastic deformation of a MG. In other words, the plasticity of a MG is determined by its density of flow units which can be characterized by the density variation upon annealing, and the MG with high density of flow units will have higher value of Poisson's ratio and larger plasticity. For a MG with larger Poisson's ratio, it has more flow units, larger density change upon annealing and will show better plasticity, and vice versa. The correlation between Poisson's ratio and $\Delta \rho$ is helpful for plastic MG designing through increase of the concentration of flow units 
in a MG [21-25, 41, 44-45].

Figure 4 schematically illustrates information about the relationship among density change, flow units, fragility and dynamic heterogeneity of glass-forming liquid, and structural heterogeneity of MG. The red and violet atoms represent the defects of flow units in MGs. For the strong metallic liquid with the smaller fragility, the corresponding MG has lower concentration of flow units comparing to that of the fragile metallic liquid. The relative density change and concentration of flow units variation of strong MG is smaller than that of the fragile MGs. The relative density change can reflect the fragility, and the degree of heterogeneity of MGs which is consistent with simulation prediction [28].

\section{Conclusions}

We obtain the interrelationship between the density variation and kinetic fragility and Poisson's ratio in metallic glasses. The relationships connect the structural heterogeneity of MG with the dynamic heterogeneity of metallic glass-forming liquid and mechanical behavior, which can help us to understand the fragility, mechanical properties, structural heterogeneity, and structural and property inheritance in MGs.

\section{Acknowledgements}

The experimental assistance and insightful discussions with D. Q. Zhao, H. Y. Bai, P. Wen, D. W. Ding and Y. T. Sun are appreciated. This work was supported by the NSF of China (Grant Nrs: 51322103 and 51271195) and MOST 973 Program of China (No. 2015CB856800). 


\section{References}

[1] O. Haruyama and A. Inoue, Appl. Phys. Lett. 88, 131906 (2006).

[2] W. H. Wang, R. J. Wang, W. T. Yang, B. C. Wei, P. Wen, D. Q. Zhao and M. X. Pan, J. Mater. Res. 17, 1385 (2002).

[3] Y. Li, Q. Guo, J.A. Kalb, C.V. Thompson, Science 322, 1816 (2008).

[4] R. J. Xue, D. P. Wang, Z. G. Zhu, D. W. Ding, B. Zhang, and W. H. Wang, J. Appl. Phys. 114, 123514 (2013).

[5] W. Dmowski, T. Iwashita, C. P. Chuang, J. Almer and T. Egami, Phys. Rev. Lett. 105, 205502 (2010).

[6] H. B. Yu, Z. Wang, W. H. Wang and H. Y. Bai, Phys. Rev. Lett. 108, 015504 (2012).

[7] Z. Wang, P. Wen, L. S. Huo, H. Y. Bai, and W. H. Wang, Appl. Phys. Lett. 101, 121906 (2012).

[8] W. Jiao, P. Wen, H. L. Peng, H. Y. Bai, B. A. Sun and W. H. Wang, Appl. Phys. Lett. 102, 101903 (2013).

[9] S. T. Liu, Z. Wang, H. L. Peng, and W. H. Wang, Scripta Mater. 67, 9 (2012).

[10] Y. Yang, J. F. Zeng, J. C. Ye and J. Lu, Appl. Phys. Lett. 97, 261905 (2010).

[11] Z. Wang, B. A. Sun, H. Y. Bai and W. H. Wang, Nature Commun. 5, 5823 (2014).

[12] H. Wagner, D. Bedorf, S. Kuchemann, M. Schwabe, B. Zhang, W. Arnold and K. Samwer, Nature Mater. 10, 439 (2011).

[13] J. C. Ye, J. Lu, C. T. Liu, Q. Wang and Y. Yang, Nature Mater. 9, 619 (2010).

[14] P. Schall, D. A. Weitz and F. Spaepen, Science 318, 1895 (2007).

[15] K. W. Park, C. M. Lee, M. Wakeda, Y. Shibutani, M. L. Falk and J. C. Lee, Acta Mater. 56, 5440 (2008).

[16] X. Q. Gao, W. H. Wang, and H. Y. Bai, J. Mater. Sci. Technol. 30, 546 (2014).

[17] H. B. Ke, P. Wen, W. H. Wang and A. L. Greer, Scr. Mater. 64, 966 (2011).

[18] F. Spaepen, Acta Metall. 25, 407 (1977).

[19] M. H. Cohen and D. Turnbull, J. Chem. Phys. 31, 1164 (1959). 
[20] A. J. Kovacs, R. A. Stratton and J. D. Ferry, J. Phys. Chem. 67, 152 (1963).

[21] C. A. Angell, J. Non-Cryst. Solids 73, 1 (1985).

[22] R. Böhmer and C. A. Angell, Phys. Rev. B 45, 10091 (1992).

[23] C. A. Angell, Science 267, 1924 (1995).

[24] N. A. Mauro, M. Blodgett, and K. F. Kelton, Nat. Commun. 5, 4616 (2014).

[25] P. G. Debenedetti and F. H. Stillinger, Nature 410, 259 (2001).

[26] D. Ma, A. D. Stoica, X. L. Wang, Z. P. Lu, B. Clausen, and D. W. Brown, Phys. Rev. Lett. 108, 085501 (2012).

[27] W. H. Wang, Nature Mater, 11, 275 (2012).

[28] S. Sastry, Nature 409, 164 (2001).

[29] M. D. Ediger and P. Harrowell, J. Chem. Phys. 137, 080901 (2012).

[30] S. C. Glade, R. Busch, D. S. Lee, W. L. Johnson, R. K. Wunderlich and H. J. Fecht, J. Appl. Phys. 87, 7242 (2000).

[31] J. F. Löffler, J. Schroers and W. L. Johnson, Appl. Phys. Lett. 77, 681 (2000).

[32] Z. Evenson, T. Schmitt, M. Nicola, I. Gallino and R. Busch, AIP Conf. Proc. 1518, 197 (2013).

[33] P. Yu, H. Y. Bai and W. H. Wang, J. Mater. Res. 21, 1674 (2006).

[34] D. N. Perera, J. Phys.: Condens. Matter 11, 3807 (1999).

[35] S. Li, R. J. Wang, M. X. Pan, W. H. Wang, J. Non-Cryst. Solids 354, 1080 (2008).

[36] B. Zhang, R. J. Wang, and W. H. Wang, Phys. Rev. B 70, 224208 (2004).

[37] W. K. An, X. Xiong, A. H. Cai, Trans. Nonferrous Met. Soc. China 23, 3312 (2013).

[38] S. F. Swallen, K. L. Kearns, M. K. Mapes, Y. S. Kim, R. J. McMahon, M. D. Ediger, T. Wu, L. Yu and S. Satija, Science 315, 353 (2007).

[39] H. S. Chen, J. T. Krause, and E. Coleman, J. Non-Cryst. Solids 18, 157 (1975).

[40] J. J. Lewandowski, W. H. Wang, and A. L. Greer, Philos. Mag. Lett. 85, 77 (2005).

[41] W. H. Wang, J. Appl. Phys. 99, 093506 (2006).

[42] W. H. Wang, Prog. Mater. Sci. 57, 487 (2012). 
[43] J. Schroers and W. Johnson, Phys. Rev. Lett. 93, 255506 (2004).

[44] V. N. Novikov, Y. Ding and A. P. Sokolov, Phys. Rev. E 71, 061501 (2005).

[45] J. Q. Wang, W. H. Wang, Y. H. Liu, and H. Y. Bai. Phys Rev. B 83, 012201 (2011) 
Table I. The fitting parameters of $A, \mathrm{~B}$, and $\beta$ of $\mathrm{Cu}_{47} \mathrm{Zr}_{11} \mathrm{Ti}_{34} \mathrm{Ni}_{8}$, $\mathrm{Pd}_{40} \mathrm{Ni}_{10} \mathrm{Cu}_{30} \mathrm{P}_{20}, \quad$ vit105, $\quad\left(\mathrm{Cu}_{50} \mathrm{Zr}_{50}\right)_{92} \mathrm{Al}_{8}, \quad \mathrm{Zr}_{65} \mathrm{Al}_{7.5} \mathrm{Ni}_{10} \mathrm{Cu}_{17.5}$, $\mathrm{La}_{55} \mathrm{Al}_{25} \mathrm{Co}_{20}, \mathrm{Ce}_{68} \mathrm{Al}_{10} \mathrm{Cu}_{20} \mathrm{Co}_{2}$ and $\mathrm{Zr}_{61.5} \mathrm{Al}_{10.7} \mathrm{Ni}_{14.15} \mathrm{Cu}_{13.65} \mathrm{MGs}$ for their flow units evolution at $0.88 T_{\mathrm{g}}$. The flow units $c$ evolution upon annealing is well fitted by Eq.(1) with $c=[A /(B+t)]^{\wedge} \beta$ for these MGs.

\begin{tabular}{lccc}
\hline \hline \multicolumn{1}{c}{ Glass } & $\boldsymbol{\beta}$ & $\boldsymbol{A}$ & $\boldsymbol{B}$ \\
\hline $\mathbf{C u}_{\mathbf{4 7}} \mathbf{Z r}_{\mathbf{1 1}} \mathbf{T i}_{\mathbf{3 4}} \mathbf{N i}_{\mathbf{8}}$ & 1.368 & 0.855 & 25.602 \\
$\mathbf{P d}_{\mathbf{4 0}} \mathbf{N i}_{\mathbf{1 0}} \mathbf{C u}_{\mathbf{3 0}} \mathbf{P}_{\mathbf{2 0}}$ & 0.103 & $8.620 \times 10^{-22}$ & 0.066 \\
$\mathbf{V i t 1 0 5}$ & 0.115 & $1.242 \times 10^{-19}$ & 0.173 \\
$\left(\mathbf{C u}_{\mathbf{5 0}} \mathbf{Z r}_{\mathbf{5 0}}\right)_{\mathbf{9 2}} \mathbf{A l} \mathbf{l}_{\mathbf{8}}$ & 0.162 & $1.652 \times 10^{-14}$ & 0.559 \\
$\mathbf{Z r}_{\mathbf{6 5}} \mathbf{A l}_{\mathbf{7 . 5}} \mathbf{N i}_{\mathbf{1 0}} \mathbf{C u}_{\mathbf{1 7 . 5}}$ & 0.210 & $4.441 \times 10^{-12}$ & 0.642 \\
$\mathbf{L a}_{\mathbf{5 5}} \mathbf{A l}_{\mathbf{2 5}} \mathbf{C o}_{\mathbf{2 0}}$ & 1.667 & 0.299 & 10.43 \\
$\mathbf{C e}_{\mathbf{6 8}} \mathbf{A l}_{\mathbf{1 0}} \mathbf{C u}_{\mathbf{2 0}} \mathbf{C o}_{\mathbf{2}}$ & 1.073 & 0.067 & 30.350 \\
$\mathbf{Z r}_{\mathbf{6 1 . 5}} \mathbf{A l}_{\mathbf{1 0 . 7}} \mathbf{N i}_{\mathbf{1 4 . 1 5}} \mathbf{C u}_{\mathbf{1 3 . 6 5}}$ & 1.303 & 0.005 & 1.014 \\
\hline \hline
\end{tabular}




\section{Figure captions}

Figure 1. The relative variation of density $\Delta \rho(\%)$ vs. $t$ (hrs) of $\mathrm{Cu}_{47} \mathrm{Zr}_{11} \mathrm{Ti}_{34} \mathrm{Ni}_{8}$, $\mathrm{Pd}_{40} \mathrm{Ni}_{10} \mathrm{Cu}_{30} \mathrm{P}_{20}$, vit105, $\left(\mathrm{Cu}_{50} \mathrm{Zr}_{50}\right)_{92} \mathrm{Al}_{8}, \mathrm{Zr}_{65} \mathrm{Al}_{7.5} \mathrm{Ni}_{10} \mathrm{Cu}_{17.5}, \mathrm{La}_{55} \mathrm{Al}_{25} \mathrm{Co}_{20}$, $\mathrm{Ce}_{68} \mathrm{Al}_{10} \mathrm{Cu}_{20} \mathrm{Co}_{2}$ and $\mathrm{Zr}_{61.5} \mathrm{Al}_{10.7} \mathrm{Ni}_{14.15} \mathrm{Cu}_{13.65} \mathrm{MGs}$ with different fragilities annealed at $0.88 T_{\mathrm{g}}$. The density $\rho$ evolution upon annealing can be well fitted by $\rho=\rho(\infty) /(1+c)$.

Figure 2. (a) The relative variation of density $\Delta \rho(\%)$ vs. fragility of these eight MGs at $0.88 T_{\mathrm{g}}$ for $128 \mathrm{hrs}$. (b) Poisson's ratio $v$ vs. the relative variation of density $\Delta \rho(\%)$ of these eight MGs at $0.88 T_{\mathrm{g}} 128 \mathrm{hrs}$.

Figure 3. The relative density changes $\Delta \rho$ vs. concentration of flow unit variations $\Delta c$ of the MGs annealed at $0.88 T_{\mathrm{g}}$ for $128 \mathrm{hrs}$. The inset shows the normalized density change $\rho / \rho_{0}$ vs. normalized concentration of flow unit variation $c / c_{0}$ of eight MGs at $0.88 T_{\mathrm{g}}$ for various times.

Figure 4. Schematic illustrations shows relationships among the relative density change, the fragility, concentration of flow unit variation of fragile to strong MGs, the connection of the structural heterogeneity with its dynamic heterogeneity in MGs. The violet and red atoms areas represent the flow unit in MGs with higher potential energies and looser packing densities compared with the relatively homogenous and denser packed matrix denoted by the blue atoms. 


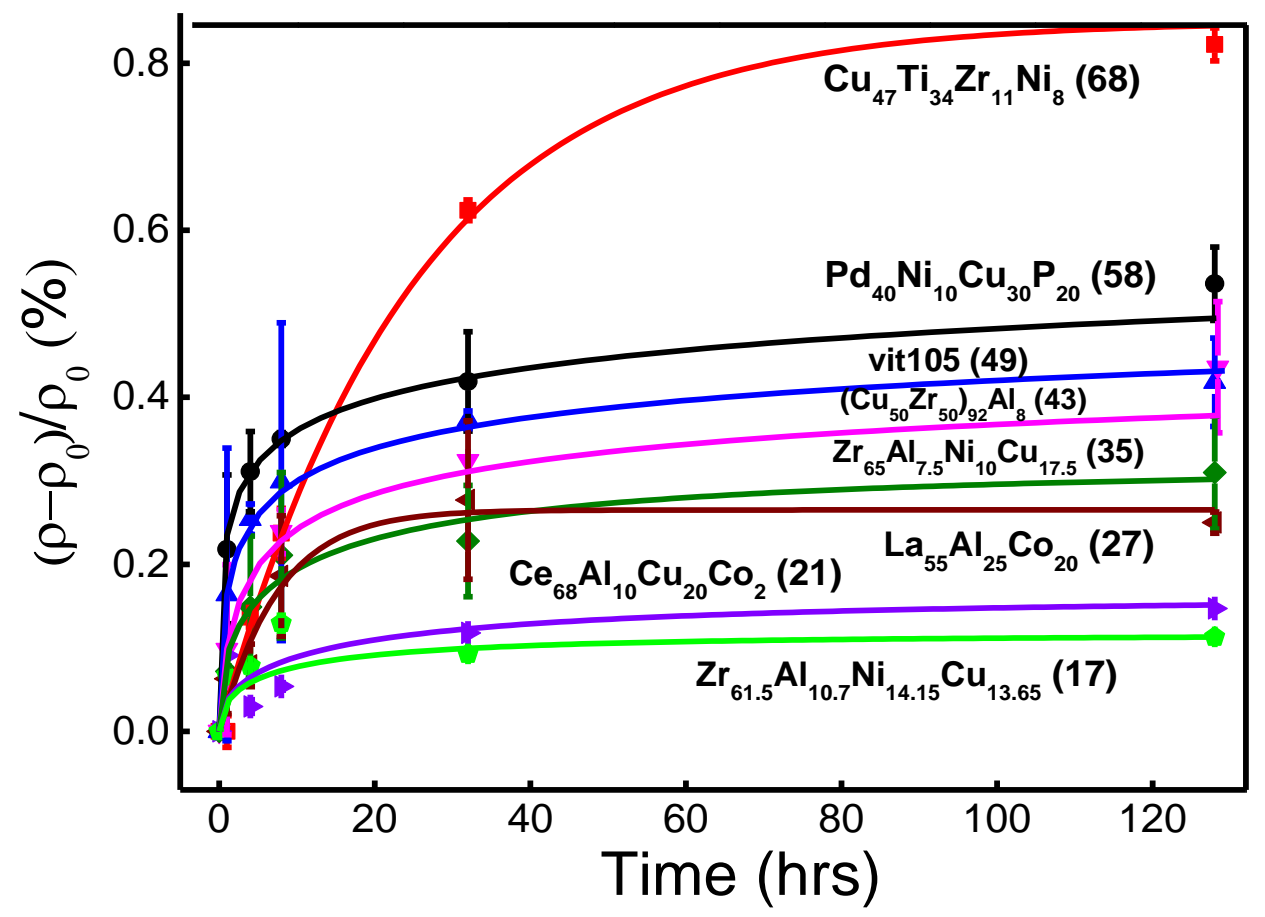

Fig.1 Xue et al 

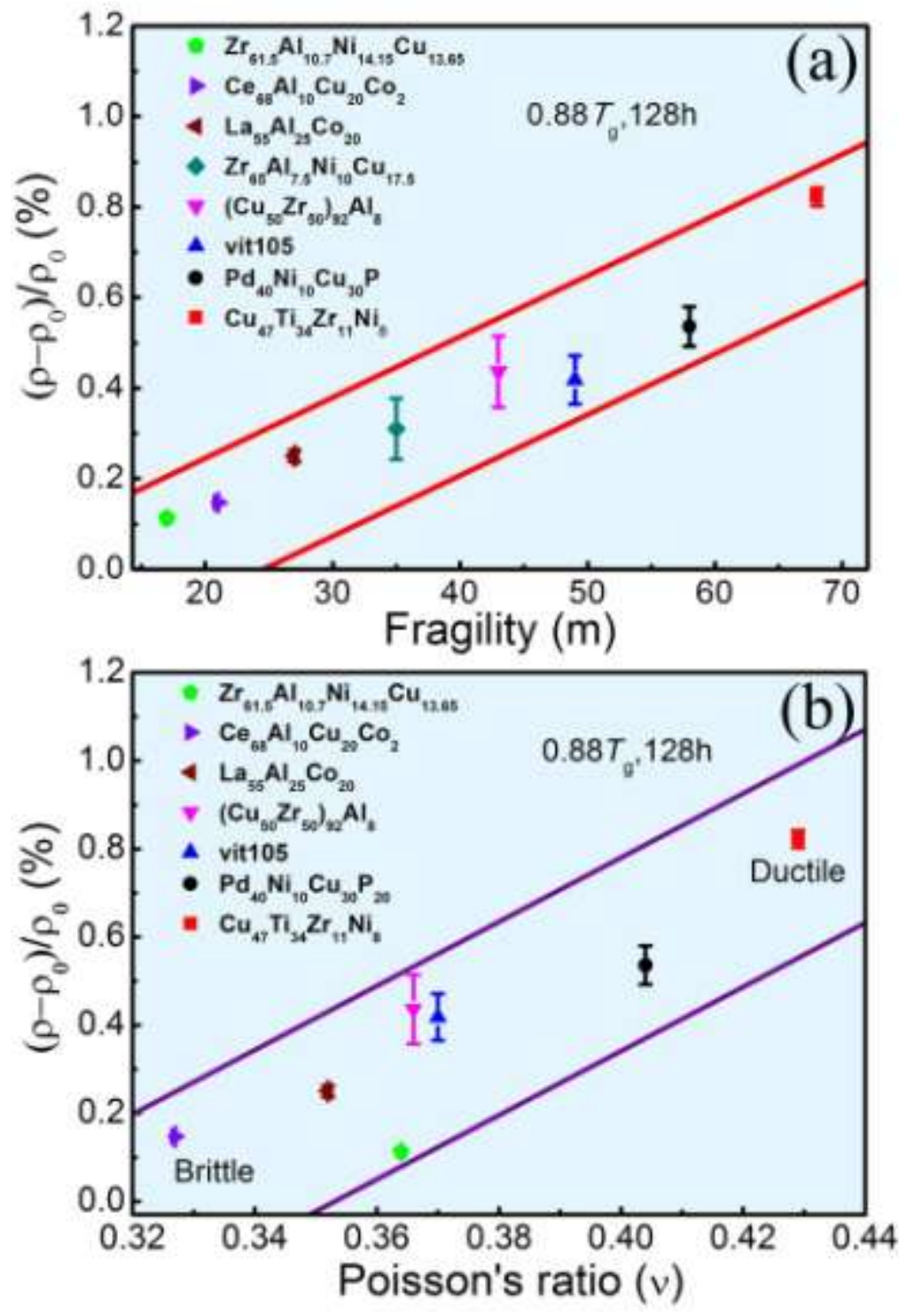

Fig. 2 Xue et al 


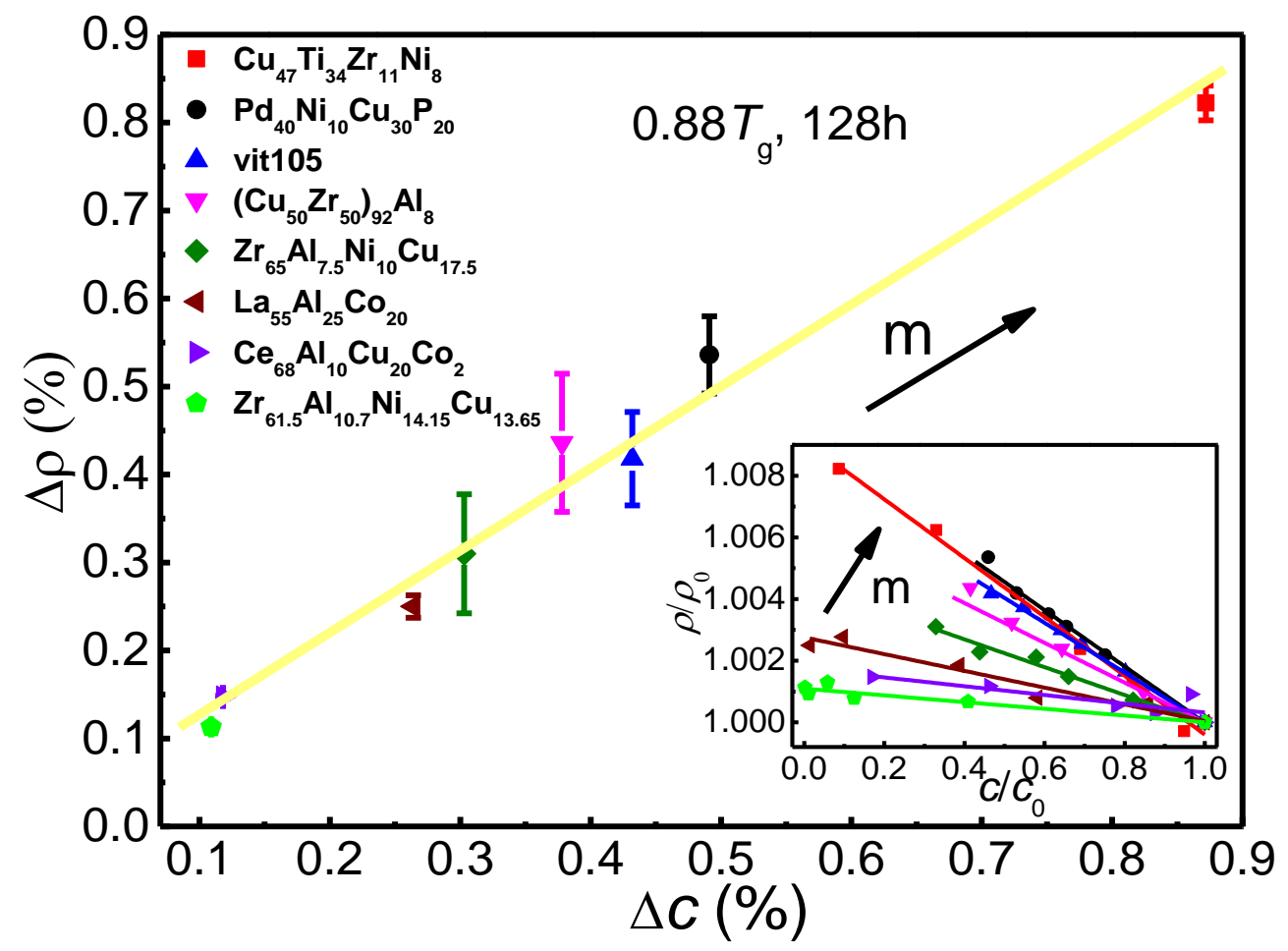

Fig.3 Xue et al 


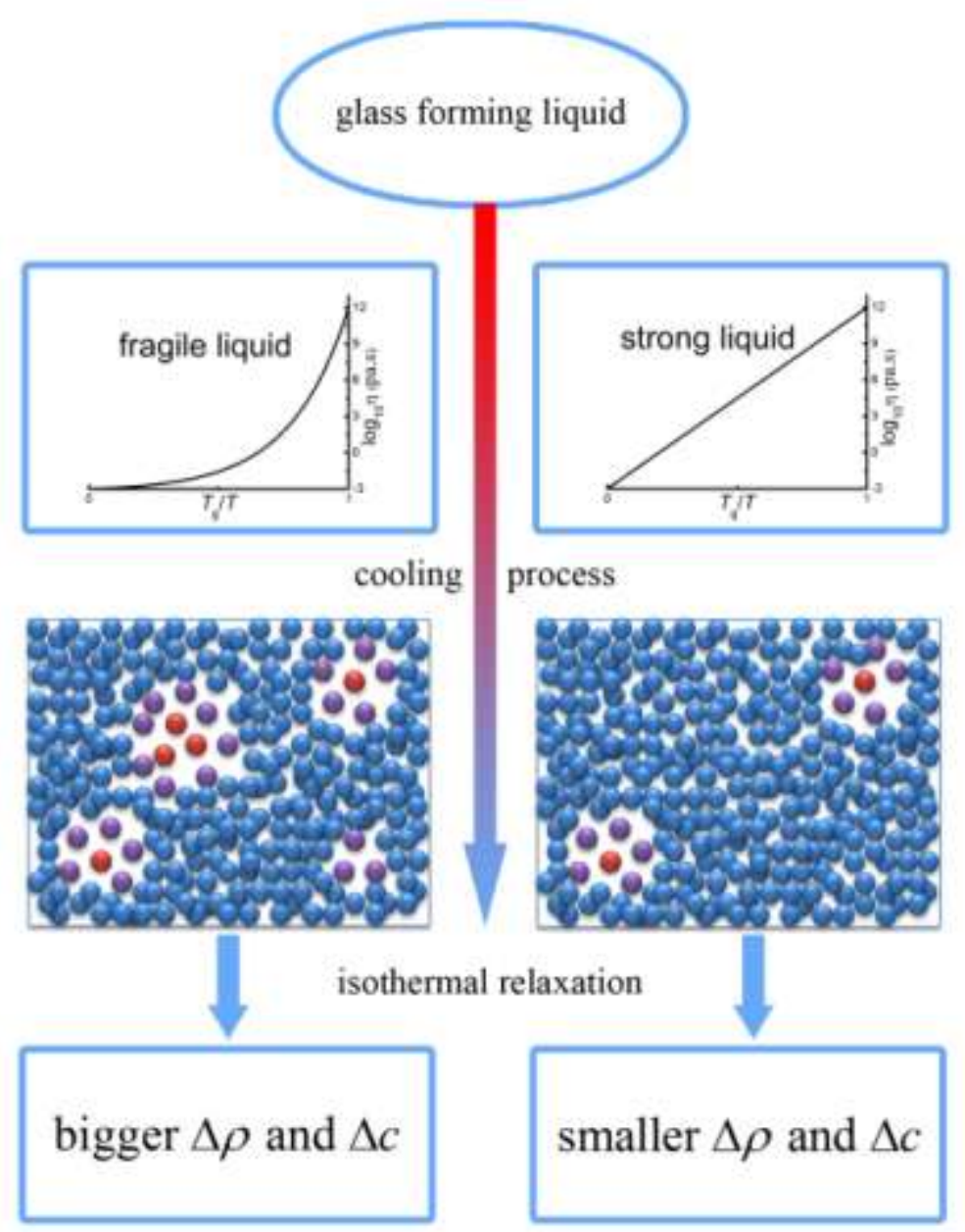

Fig.4 Xue et al 